\title{
Room for improvement: One third of Lynch syndrome patients presenting for genetic testing in a highly specialised centre in Stockholm already have cancer
}

\author{
Sophie Walton Bernstedt ${ }^{1,2}$ (D) Jan Björk ${ }^{1,2,3}$ (D) Kaisa Fritzell ${ }^{3,4}$ (D) Allan D. Spigelman ${ }^{5,6}$ (D) Erik Björck ${ }^{7,8}$ and
} Ann-Sofie Backman ${ }^{1,2,3^{*}}$ (i)

\begin{abstract}
Background: Lynch syndrome is caused by germline mutations in the mismatch repair genes and is characterised by a familial accumulation of colorectal and other cancers. Earlier identification of Lynch syndrome patients enables surveillance and might reduce the risk of cancer. It is important to explore whether today's clinical care discovers patients with Lynch syndrome suitable for surveillance in time. This study aimed to describe what led to a diagnosis of Lynch syndrome in the cohort referred to the Hereditary Gastrointestinal Cancer Unit, Karolinska University Hospital, Solna, Sweden for gastrointestinal surveillance.

Methods: This was a descriptive study. Data from 1975 to 2018 were collected and compiled as a database. Age at diagnosis was calculated from the date when a pathogenic MMR gene mutation was confirmed, from the period June 1994-September 2018. Data were collected from patient protocols prospectively during patient consultations and medical records retrospectively. Criteria for inclusion were registration at the outpatient clinic and a confirmed mismatch repair gene mutation.
\end{abstract}

Results: A total of 305 patients were eligible for inclusion. Three major reasons for diagnosis were identified: 1. Predictive testing of a previously known mutation in the family (62\%, mean age 37$)$, 2. A family history of Lynch associated tumours (9\%, mean age 37$)$, 3. A diagnosis of cancer (29\%, mean age 51$)$. The proportion diagnosed due to cancer has not changed over time.

Conclusion: A high proportion of patients (29\%) were identified with Lynch syndrome after they had been diagnosed with an associated cancer, which suggests that there is significant room for improvement in the diagnosis of patients with Lynch syndrome before cancer develops.

Keywords: Lynch syndrome, Colorectal cancer, Genetic testing, Mismatch repair genes, Cancer prevention

\footnotetext{
* Correspondence: ann-sofie.backman@sll.se

'Department of Medicine Solna, Karolinska Institutet, Stockholm, Sweden

${ }^{2}$ Division of Gastroenterology, Medical Unit Gastroenterology,

Dermatovenereology and Rheumatology, Karolinska University Hospital,

Stockholm, Sweden

Full list of author information is available at the end of the article
}

\section{$\triangle B M C$}

(c) The Author(s). 2021 Open Access This article is licensed under a Creative Commons Attribution 4.0 International License, which permits use, sharing, adaptation, distribution and reproduction in any medium or format, as long as you give appropriate credit to the original author(s) and the source, provide a link to the Creative Commons licence, and indicate if changes were made. The images or other third party material in this article are included in the article's Creative Commons licence, unless indicated otherwise in a credit line to the material. If material is not included in the article's Creative Commons licence and your intended use is not permitted by statutory regulation or exceeds the permitted use, you will need to obtain permission directly from the copyright holder. To view a copy of this licence, visit http://creativecommons.org/licenses/by/4.0/ The Creative Commons Public Domain Dedication waiver (http://creativecommons.org/publicdomain/zero/1.0/) applies to the data made available in this article, unless otherwise stated in a credit line to the data. 


\section{Introduction}

Lynch syndrome (LS) is caused by germline mutations in the mismatch repair genes and is characterised by an increased risk of developing colorectal cancer at a young age, slightly more frequent localisation of the tumour in the proximal colon and accumulation of colorectal and extracolonic cancers.

Early identification of those at high genetic risk of cancer might save lives because surveillance programmes would be indicated. Historically, in the absence of a known genetic cause, the primary diagnostic tool was an extensive family history. Vasen et al. [1] later introduced clinical criteria in 1991, known as the Amsterdam criteria 1, augmented by the Bethesda guidelines [2]. At present, the gold standard method to diagnose LS is by pedigree criteria and DNA sequencing. Due to the high lifetime risk of colorectal cancer (CRC) and endometrial cancer (EC), patients with LS are offered surveillance by means of colonoscopy and prophylactic hysterectomy. However, surveillance and prophylactic surgery only works if it is started in a timely manner given that the purpose is to prevent cancer. If genetic testing is offered in a limited way then a large proportion of patients at risk will remain undiagnosed until they present with cancer.

We wanted to explore to what extent clinical care discover patients with LS suitable for surveillance before the diagnosis of cancer. There are approximately 910 known individuals with Lynch syndrome in Sweden [3]. However, there are probably many undiagnosed cases as studies have indicated the prevalence of Lynch syndrome in the United States to be as high as 1/440 [4], which would correspond to a Swedish prevalence of 23,700 individuals. In Sweden 6000 cases of CRC [5] are diagnosed annually. Lynch syndrome is estimated to account for $2.2 \%$ of colorectal cancer cases in the US [6]. It is important to detect individuals with Lynch syndrome at an early age to offer surveillance to minimise the risk of developing cancer. The aim of the current study was to investigate causes what led to a diagnosis of LS and to identify changes over time among LS patients referred for endoscopic surveillance at Karolinska University Hospital, a highly specialised Swedish centre.

\section{Materials and methods}

\section{Cohort description}

Patients referred to the Hereditary GI Cancer Unit, Karolinska University Hospital, Sweden, for gastrointestinal surveillance, with a confirmed MMR gene mutation according to InSight Variant Interpretation Committee's classification [7], or if the variant was unknown (class 3), reported to be pathogenic by the hospital's genetics department after clinical evaluation based on family history were included. Approximately one third of Swedish patients with LS are followed at this clinic at the Karolinska University Hospital in Stockholm. This hospital has a catchment area that primarily includes Stockholm County, but acts as a second opinion hospital for north and mid-Sweden. The hospital has 1600 beds [8]. In 2018, Stockholm County had a population of around 2,3 million people [9] compared to Sweden as a whole which had a population of approximately 10 million [10].

\section{Data collection}

Data from 1975 to 2018 were collected and compiled as a database (Table 1). Age at diagnosis was calculated from the date when a pathogenic MMR gene mutation was confirmed, from the period June 1994-September 2018. Data were collected from patient protocols prospectively during patient consultations and medical records retrospectively.

\section{Variables}

Possible reasons for investigation for LS were categorised as 1) predictive testing, 2) family history or 3) cancer, i.e. CRC, EC or skin tumour. Predictive testing was defined as when a person at risk is referred within the healthcare system to be tested for an MMR mutation that had previously been identified in the family. Family history was defined as when a patient was referred within the healthcare system to investigate whether they had Lynch syndrome or another hereditary cancer syndrome based on the family history of malignancies. Data regarding age, sex, cancer diagnoses (anatomical site and age at diagnosis and year of diagnosis) were collected.

Table 1 Demographic and clinical data on patients with Lynch syndrome in Stockholm County during the period June 1994September 2018

\begin{tabular}{ll}
\hline Characteristic & N: $\mathbf{3 0 5}(\%)$ \\
\hline Gender & \\
Female & $170(56 \%)$ \\
Male & $135(44 \%)$ \\
Age at diagnosis, mean (range) & 41 years (16-93) \\
Age at inclusion, mean (range) & 45 years (16-92) \\
Registered in Stockholm County & $282(92 \%)$ \\
Deceased & $13(4 \%)$ \\
Index visit & $235(77 \%)$ \\
Genotype & \\
MLH1 & $142(47 \%)$ \\
MSH2 & $83(27 \%)$ \\
MSH6 & $43(14 \%)$ \\
PMS2 & $30(10 \%)$ \\
EPCAM & $6(2 \%)$ \\
\hline
\end{tabular}


The genetic variants were verified for pathogenicity using the InSight Variant Interpretation Committee's classification [7].

\section{Statistics}

Descriptive statistics are presented as mean, range, proportions and percentages, comparison of data was made using Fischer's exact test. Continuous data were evaluated to be normally distributed and were analysed using the Student's t-test. Statistical significance was set at $P<$ 0.05 with a confidence interval of $95 \%$.

\section{Results}

Of the 336 LS patients registered in the clinic; 305 were eligible for inclusion. Of the 305 patients 13 were found to be deceased, seven due to cancer-related causes. Five patients had missing information regarding cause of death and one patient had a cause of death not related to cancer. One patient was found to have mutations affecting multiple MMR genes (MLH1 and PMS2). Patient demographic are shown in Table 1.

\section{Reasons for investigation leading to diagnosis of Lynch syndrome}

Three major reasons were investigated 1 . Pre-symptomatic predictive testing of previously known mutation in the family $(62 \%, n=190$, mean age 37$), 2$. Family history of Lynch associated tumours ( $9 \%, n=27$, mean age 37$), 3$. Diagnosis of cancer (29\%, $n=88$, mean age 51) (Fig. 1.).

Of those with cancer almost half $(51 \%, n=45)$ had a family history consistent with LS or a familial known $M M R$ gene mutation. The mean age at diagnosis of LS was 41 years (range 16-93 years). Those diagnosed due to any cancer were older than those diagnosed due to predictive testing and family history combined (mean 51 years, CI $48-53$ years; mean 37 years, CI $35-39$ years: $P<0.01)$. Those diagnosed with LS due to a diagnosis of CRC were diagnosed with CRC at a mean age of 44 years (range 24-75 years). There was no statistical significant difference in the cause for LS diagnosis observed between female and male patients regarding diagnosis due to cancer $(28 \%$, CI $22-36 ; 30 \%$, CI 22-38: $P=0.80)$.

\section{Lynch syndrome - diagnosed due to cancer}

Age at the diagnosis of cancer and the tumour spectrum that led to the diagnosis of LS is shown in Table 2. Patients $(n=88)$ diagnosed with LS due to a diagnosis of cancer were most frequently diagnosed due to CRC $(n=$ 67, 76\%) (Table 2). As a single diagnosis of cancer, CRC amounted to $72 \%(n=63)$. Other single diagnoses of cancer that led to a diagnosis of LS were EC $(n=16$, $18 \%)$, skin tumours $(n=3,3 \%)$ and ovarian cancer $(n=1$,

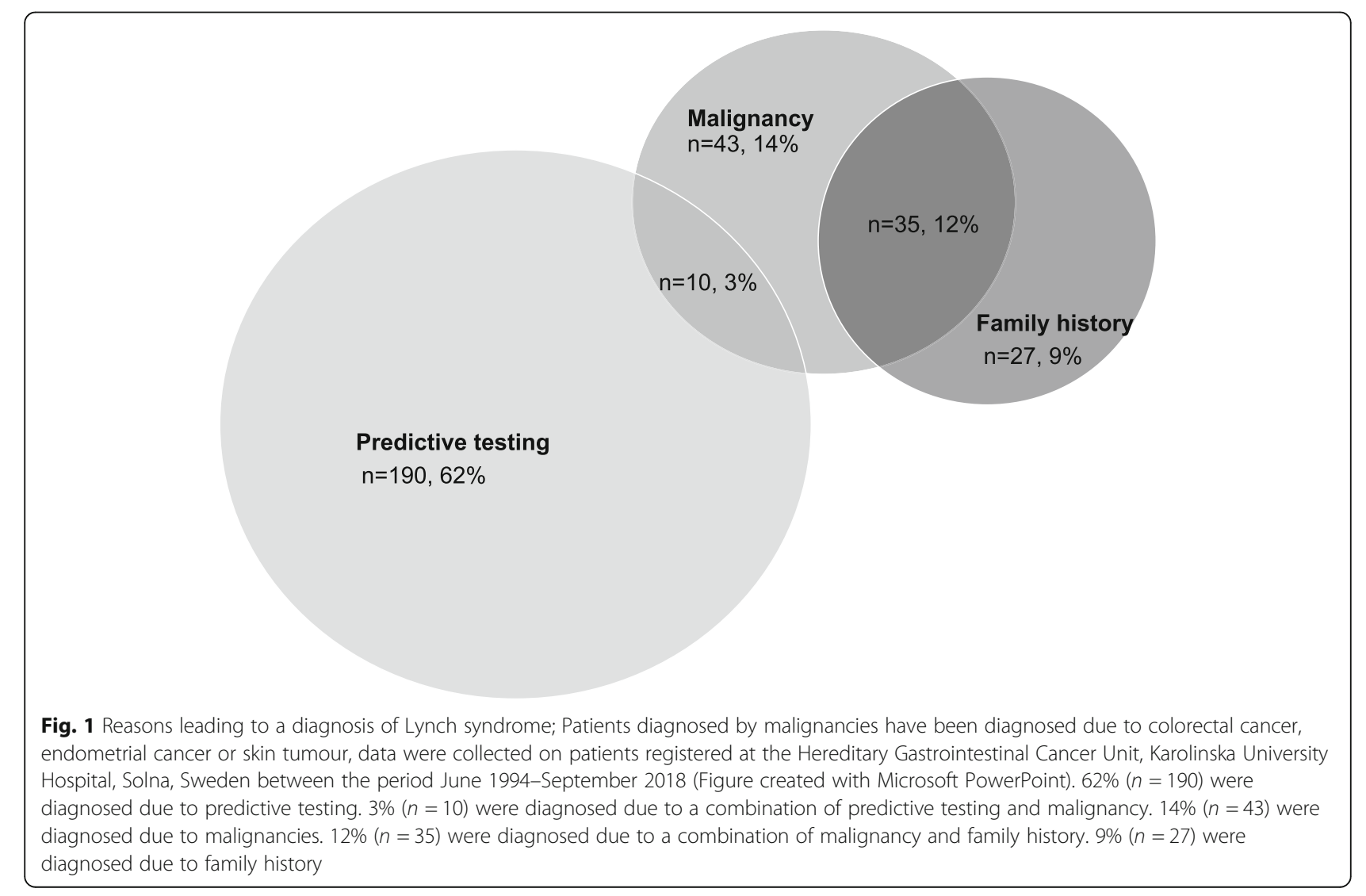


Table 2 Tumour spectrum and age at diagnosis of each tumour leading to a diagnosis of Lynch syndrome

\begin{tabular}{lll}
\hline Patients & N:88 (\%) & $\begin{array}{l}\text { Age at diagnosis } \\
\text { mean (range) }\end{array}$ \\
\hline Colorectal cancer & $67(76 \%)$ & $(44,24-75)$ \\
Extracolonic cancer & $25(28 \%)$ & $(49,24-65)$ \\
Gynaecological cancer & $21(24 \%)$ & $(49,38-65)$ \\
Skin tumour & $4(5 \%)$ & $(45,24-58)$ \\
Total number of tumours $^{\mathrm{a}}$ & 117 & \\
\hline
\end{tabular}

${ }^{a}$ Five (6\%) patients had multiple cancer diagnoses that led to a diagnosis of Lynch syndrome

$1 \%)$. Five $(6 \%)$ patients had multiple cancer diagnoses that led to a diagnosis of LS.

Most patients $(78 \%, n=52)$ with a diagnosis of CRC that led to a diagnosis of Lynch syndrome were diagnosed with CRC due to anaemia and/or symptoms. Four patients were diagnosed in the context of a general endoscopic CRC screening programme or due to endoscopic surveillance motivated by a family history of CRC. Four patients were diagnosed due to other CRC surveillance such as a general CRC surveillance programme or due to a family history of CRC. Eleven patients had missing information regarding cause of $\mathrm{CRC}$ diagnosis.

Those patients who were diagnosed with gynaecological cancer, presented most often with symptoms such as uterine bleeding and abdominal discomfort $(71 \%, n=15)$. Other causes leading to a diagnosis of gynaecological cancer were follow-up examination due to CRC, follow-up due to a family history of cancer and follow-up due to miscarriage. Of those patients diagnosed due to skin tumours, three were suspected of having LS due to the presence of sebaceous tumours and one patient had dysplastic nevi.

\section{Reasons for diagnosis of Lynch syndrome in patients at or over 60 years of age}

Reasons for diagnosis of Lynch syndrome in relation to age, $n=305$, are described in Fig. 2. LS was diagnosed in 36 patients at or over 60 years of age. Among these, the majority $(n=20,56 \%)$ had received their diagnosis in relation to a diagnosis of cancer. A third $(n=12,33 \%)$ explicitly requested a genetic investigation. Other reasons that warranted genetic investigation included making genetic screening available for relatives $(n=8,22 \%)$, offering preventive measures such as endoscopies, hysterectomy and adequate follow-up after cancer $(n=12$, $33 \%)$ and research purposes $(n=4,11 \%)$.

\section{Reasons for investigation leading to diagnosis of Lynch syndrome - time trend}

Figure $3 \mathrm{a}$ shows the number of cases diagnosed with Lynch syndrome over time year by year in relation to

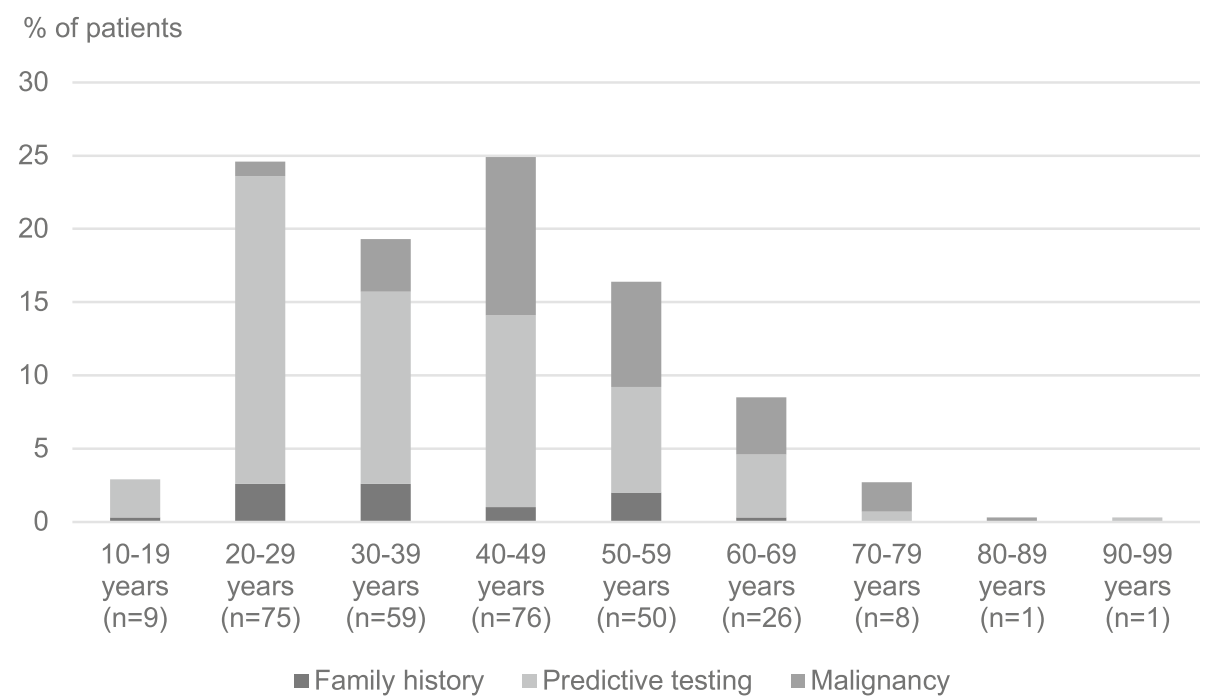

Fig. 2 Reason for diagnosis of Lynch syndrome in relation to age, $n=305$; In the age range $10-19$ years, $0.3 \%(n=1)$ were diagnosed due to family history and $2.6 \%(n=8)$ due to predictive testing. In the age range $20-29$ years $2.6 \%(n=8)$ were diagnosed due to family history, $21 \%$ $(n=64)$ were diagnosed due to predictive testing and $1 \%(n=3)$ were diagnosed due to malignancy. In the age range $30-39$ years, $2.6 \%(n=8)$ were diagnosed due to family history, $13.1 \%(n=40)$ were diagnosed due to predictive testing and $3.6 \%(n=11)$ were diagnosed due to malignancy. In the age range $40-49$ years, $1 \%(n=3)$ were diagnosed due to family history, $13.1 \%(n=40)$ were diagnosed due to predictive testing and $10.8 \%(n=33)$ were diagnosed due to malignancy. In the age range 50-59 years, $2 \%(n=6)$ were diagnosed due to family history, $7.2 \%(n=22)$ were diagnosed due to predictive testing and 7.2\% ( $n=22)$ were diagnosed due to malignancy. In the age range 60-69years, $0.3 \%$ $(n=1)$ were diagnosed due to family history, $4.3 \%(n=13)$ were diagnosed due to predictive testing and $3.9 \%(n=12)$ were diagnosed due to malignancy. In the age range 70-79years, $0.7 \%(n=2)$ were diagnosed due to predictive testing and $2 \%(n=6)$ were diagnosed due to malignancy. In the age range $80-89$ years, $0.3 \%(n=1)$ were diagnosed due to malignancy. In the age range $90-99$ years, $0.3 \%(n=1)$ were diagnosed due to malignancy 


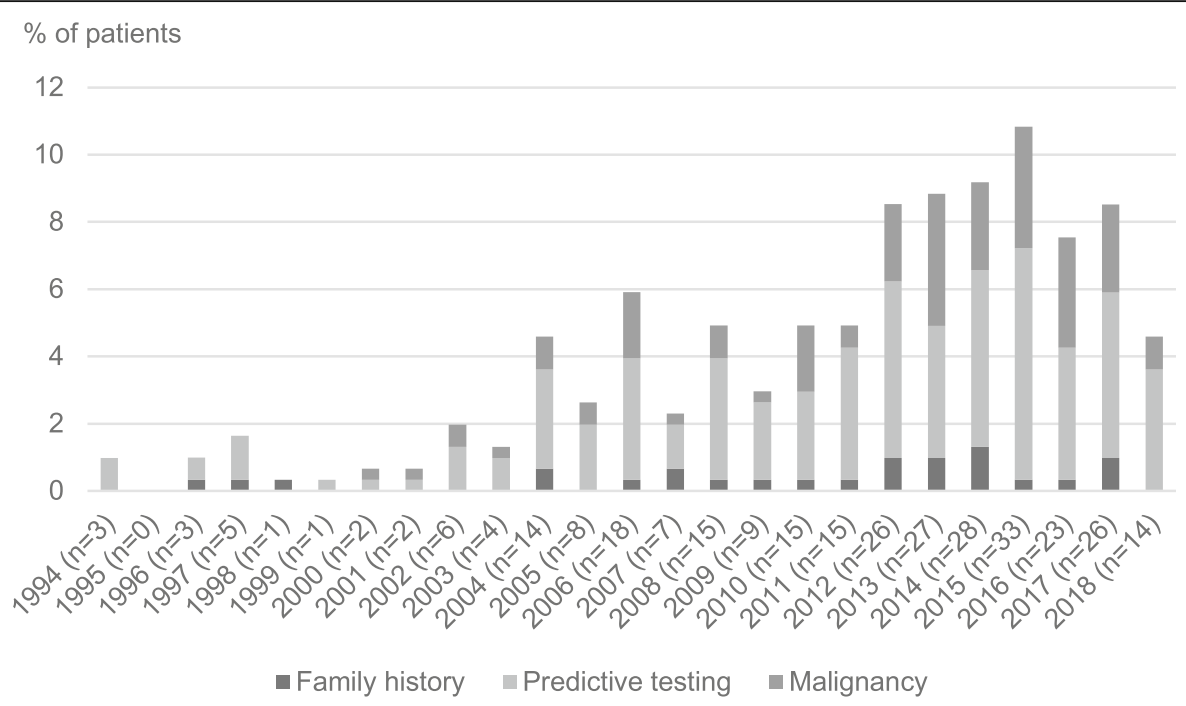

a Reason for diagnosis of Lynch syndrome over time, per year, $n=305$

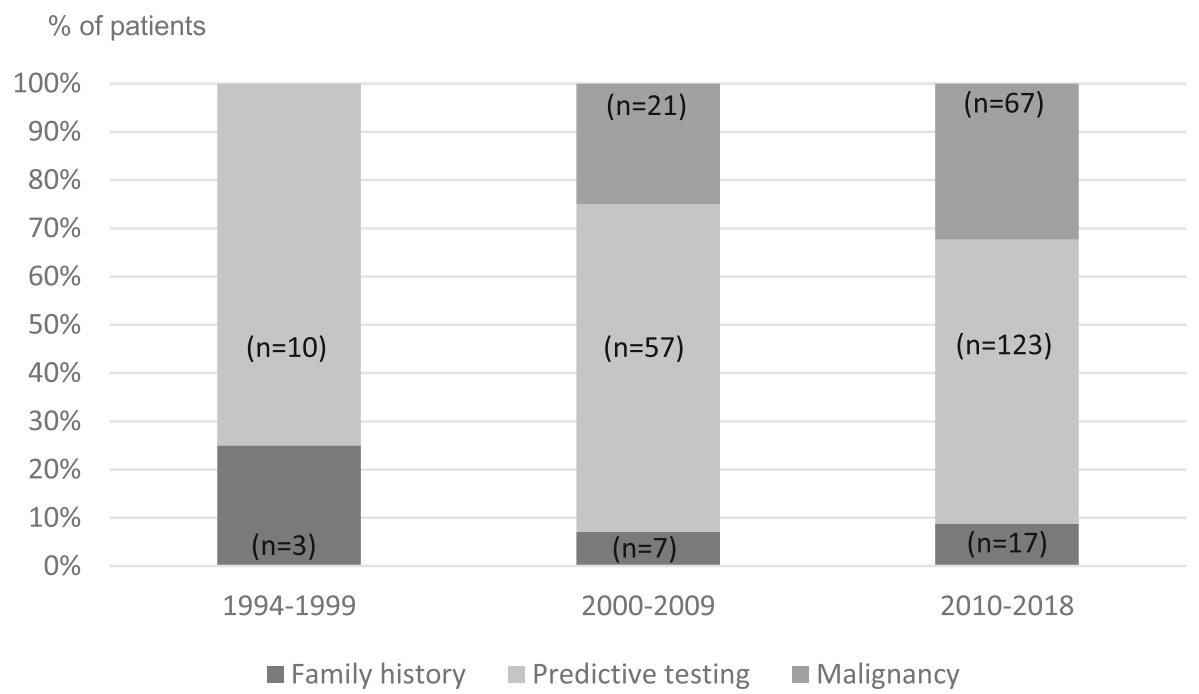

b Reason for diagnosis of Lynch syndrome over timeperiods $\mathbf{n}=\mathbf{3 0 5}$

Fig. 3 (See legend on next page.) 
(See figure on previous page.)

Fig. 3 a Reason for diagnosis of Lynch syndrome over time, per year, $n=305$; Data were collected on patients registered at the Hereditary Gastrointestinal Cancer Unit, Karolinska University Hospital, Solna, Sweden between the period June 1994-September 2018 (Figure created with Microsoft Excel). In 1994, 1\% ( $n=3)$ patients were diagnosed due to predictive testing. In 1995, 0\% $(n=0)$ patients were diagnosed. In 1996, 0.3\% $(n=1)$ were diagnosed due to family history and $0.7 \%(n=2)$ due to predictive testing. In $1997,0.3 \%(n=1)$ were diagnosed due to family history and 1.3\% $(n=4)$ were diagnosed due to predictive testing. In 1998, 0.3\% $(n=1)$ were diagnosed due to family history. In 1999, $0.3 \%(n=$ 1) were diagnosed due to predictive testing. In $2000,0.3 \%(n=1)$ were diagnosed due to predictive testing and $0.3 \%(n=1)$ were diagnosed due to malignancy. In $2001,0.3 \%(n=1)$ were diagnosed due to predictive testing and $0.3 \%(n=1)$ were diagnosed due to malignancy. In $2002,1.3 \%$ $(n=4)$ were diagnosed due to predictive testing and 0.7\% $(n=2)$ due to malignancy. In 2003, $1 \%(n=3)$ were diagnosed due to predictive testing and $0.3 \%(n=1)$ were diagnosed due to malignancy. In 2004, $0.7 \%(n=2)$ were diagnosed due to family history, $3 \%(n=9)$ were diagnosed due to predictive testing and $1 \%(n=3)$ were diagnosed due to malignancy. In $2005,2 \%(n=6)$ were diagnosed due to predictive testing and $0.7 \%(n=2)$ were diagnosed due to malignancy. In 2006, $0.3 \%(n=1)$ were diagnosed due to family history, 3.6\% $(n=11)$ due to predictive testing and $2 \%(n=6)$ due to malignancy. In 2007, $0.7 \%(n=2)$ were diagnosed due to family history, $1.3 \%(n=4)$ were diagnosed due to predictive testing and $0.3 \%(n=1)$ were diagnosed due to malignancy. In 2008, $0.3 \%(n=1)$ were diagnosed due to family history, $3.6 \%$ $(n=11)$ were diagnosed due to predictive testing and $1 \%(n=3)$ were diagnosed due to malignancy. In 2009, $0.3 \%(n=1)$ were diagnosed due to family history, $2.3 \%(n=7)$ were diagnosed due to predictive testing and $0.3 \%(n=1)$ were diagnosed due to malignancy. In 2010, $0.3 \%(n=1)$ were diagnosed due to family history, $2.6 \%(n=8)$ were diagnosed due to predictive testing and $2 \%(n=6)$ were diagnosed due to malignancy. In 2011, 0.3\% ( $n=1)$ were diagnosed due to family history, 3.9\% ( $n=12)$ were diagnosed due to predictive testing and $0.7 \%(n=2)$ were diagnosed due to malignancy. In 2012, 1\% ( $n=3)$ were diagnosed due to family history, 5.2\% $(n=16)$ were diagnosed due to predictive testing and 2.3\% ( $n=7)$ were diagnosed due to malignancy. In 2013, 1\% $(n=3)$ were diagnosed due to family history, 3.9\% $(n=12)$ were diagnosed due to predictive testing and $3.9 \%(n=12)$ were diagnosed due to malignancy. In $2014,1.3 \%(n=4)$ were diagnosed due to family history, $5.2 \%(n=$ 16) were diagnosed due to predictive testing and $2.6 \%(n=8)$ were diagnosed due to malignancy. In $2015,0.3 \%(n=1)$ were diagnosed due to family history, $6.9 \%(n=21)$ were diagnosed due to predictive testing and 3.6\% ( $n=11)$ were diagnosed due to malignancy. In 2016, $0.3 \%(n=1)$ were diagnosed due to family history, 3.9\% ( $n=12)$ were diagnosed due to predictive testing and $3.3 \%(n=10)$ were diagnosed due to malignancy. In 2017, 1\% ( $n=3)$ were diagnosed due to family history, 4.9\% $(n=15)$ were diagnosed due to predictive testing and $2.6 \%(n=8)$ were diagnosed due to malignancy. In 2018, $3.6 \%(n=11)$ were diagnosed due to predictive testing and $1 \%(n=3)$ were diagnosed due to malignancy. b. Reason for diagnosis of Lynch syndrome over timeperiods, $n=305$; Data were collected on patients registered at the Hereditary Gastrointestinal Cancer Unit, Karolinska University Hospital, Solna, Sweden between the period June 1994-September 2018 (Figure created with Microsoft Excel). In 1994-1999, 77\% ( $n=10 / 13)$ patients were diagnosed due to family history and $23 \%(n=3 / 13)$ were diagnosed due to predictive testing. In 2000-2009, 25\% ( $n=21 / 85)$ were diagnosed due to malignancy, $67 \%(n=57 / 85)$ were diagnosed due to predictive testing and $8 \%(n=7 / 85)$ were diagnosed due to family history. In 2010-2018, 32\% ( $n=67 / 207)$ were diagnosed due to malignancy, 60\% ( $n=123 / 207)$ were diagnosed due to predictive testing and $8 \%(n=17 / 207)$ were diagnosed due to family history

the reason for diagnosis. Those who received their diagnosis $2010-2018$ amounted to $68 \%(n=207 / 305)$ of the cohort and of these patients $32 \%(n=67 / 207)$ received their diagnosis due to genetic testing initiated because of a diagnosis of cancer (Fig. 3b). Cancer was found to be a cause for initiation of an investigation leading to a diagnosis in almost one third of patients between the years 2010-2018, mostly due to CRC. Between the periods 2000-2009 and 2010-2018, there has been no statistically significant change in the proportion diagnosed due to cancer $(25 \%$, CI $16-34 \%$; $32 \%$, CI $26-39 \%$ : $P=0.21)$.

\section{Discussion}

In this cohort, three major causes leading to a diagnosis of Lynch syndrome were investigated: predictive testing, cancer and family history. The most common cause for diagnosis was predictive testing. Approximately a third of patients received their diagnosis due to a previous diagnosis of cancer. It has been suggested [11] that up to $77 \%$ of relatives of patients with CRC or endometrial cancer diagnosed with Lynch syndrome are unaffected at the time of genetic testing. Win et al. [12] have also shown that $7 \%$ of patients with LS may have more than one cancer at the time of diagnosis. The most common cancer diagnosis leading to a diagnosis of LS in the current study was CRC, followed by gynaecological and skin tumours. Those diagnosed due to CRC were diagnosed at a mean age of 44 , a result similar to previous studies [13]. Most patients (69\%) received their diagnosis at 20-49 years, but patients up to 93 years in the studied cohort were investigated and found to have LS. Investigating MMR status in patients with CRC up to 70 years of age is beneficial in order to increase the detection of LS since these patients may not meet previous criteria for genetic testing [14]. Our findings support this notion and show that testing for LS in even older patients may be beneficial.

The number of patients diagnosed with LS increased over time but over the last two decades the reasons for diagnosis have not changed. More patients are thus now identified as having LS. Patients are still not identified in time to prevent cancer development, suggesting a large number of cases remaining undiagnosed. Mittendorf et al. [15] found that as many as $64 \%$ were diagnosed with a LS related malignancy prior to their diagnosis of Lynch syndrome. Mittendorf et al. [15] also found that prior to $2009,11 \%$ of patients received a diagnosis of Lynch syndrome within 1 year of a related cancer compared to after 2009 when $83 \%$ received a diagnosis. The increasing number of diagnosed patients could imply 
increasing awareness among colorectal surgeons and oncologists who now initiate genetic investigations more often in the case of cancer in a young person. It has, on the other hand, been demonstrated that LS is underrecognised, even when patients have clear criteria unrelated to family history. Singh et al. [16] found that as few as $7 \%$ of patients with CRC who meet the Bethesda guidelines were offered genetic counselling. Another study [17] showed that $11 \%$ of patients who met the Bethesda guidelines and $25 \%$ of individuals who met the Amsterdam II criteria were screened for Lynch syndrome. Adelson et al. [18] have also demonstrated that only $22 \%$ of patients $(22 / 97)$ with CRC who the Bethesda guidelines applied to underwent further investigation, and that one third of physicians underestimate the penetrance of Lynch syndrome [19] which might be improved by education and structural changes.

After a diagnosis of LS, the clinical routine in Sweden is to ask patients to inform their relatives about the option of presymptomatic predictive testing. This strategy has not been successful [20] whereas when healthcare professionals directly contact relatives the testing rate almost doubles [21]. It has been suggested that relatives may not comprehend information provided and that when adequately informed, rate of testing will increase [22, 23]. Up to $66 \%$ of relatives preferred to receive information from the hospital rather than from family members [24].

Strengths of the study include the low risk of interobserver bias, as all patient data were collected in a standardised manner in the form of protocols by just a few authors. Limitations include the relatively small sample size studied. Patients included in the study were found to have migrated from other counties and countries, accounting for some missing data. Changes in the electronic medical record systems over time also limited access to previous information.

\section{Conclusion}

We conclude that a high proportion of patients were initially identified with Lynch syndrome after they had been diagnosed with an associated cancer and that this proportion has not changed over recent years. This finding supports the importance of improving the awareness about these high risk genes among clinicians and health policy makers to increase the identification of patients with Lynch syndrome and thereby facilitate the prevention of cancer.

\section{Acknowledgements}

The authors would like to acknowledge the financial funding from the Bengt Ihre's Research Foundation.

\section{Research involving human subjects/informed consent/consent to} participate

The data this study is based on are from a quality improvement register. Informed consent is therefore not required.
Code availability

Not applicable.

\section{Authors' contributions}

Material preparation, data collection and analysis were performed by Sophie Walton Bernstedt, Jan Björk, Erik Björck and Ann-Sofie Backman. Kaisa Fritzell, Allan D Spigelman, Erik Björck, Ann-Sofie Backman contributed by reviewing and editing the manuscript. The first draft of the manuscript was written by Sophie Walton Bernstedt and all authors commented on all versions of the manuscript. All authors read and approved the final manuscript.

\section{Funding}

This study was supported with funding from the Bengt Ihre's Research Foundation, the Swedish medical association. Open Access funding provided by Karolinska Institute.

\section{Availability of data and materials}

All raw data are securely stored within the Hereditary Gastrointestinal Cancer Unit, Karolinska University Hospital.

\section{Ethics approval and consent to participate}

All the procedures being performed were part of the routine clinical care. This study was approved by the Regional Ethics Examination Board of Stockholm, Dnr 2017/2013-31/2.

\section{Consent for publication}

Not applicable.

\section{Competing interests}

The authors have no conflict of interest to declare.

\section{Author details}

${ }^{1}$ Department of Medicine Solna, Karolinska Institutet, Stockholm, Sweden. ${ }^{2}$ Division of Gastroenterology, Medical Unit Gastroenterology, Dermatovenereology and Rheumatology, Karolinska University Hospital, Stockholm, Sweden. ${ }^{3}$ Patient flow Hereditary Cancer, Cancer Theme, Karolinska University Hospital, Stockholm, Sweden. ${ }^{4}$ Department of Neurobiology, Care Sciences and Society, Division of Nursing, Karolinska Institutet, Stockholm, Sweden. ${ }^{5}$ St Vincent's Genetics Clinic, The Kinghorn Cancer Centre, Sydney, Australia. 'St Vincent's Clinical School, UNSW, Sydney, Australia. ${ }^{7}$ Department of Molecular Medicine and Surgery, Karolinska Institutet, Stockholm, Sweden. ${ }^{8}$ Clinical Genetics, Karolinska University Laboratory, Karolinska University Hospital, Stockholm, Sweden.

Received: 10 November 2020 Accepted: 19 January 2021

Published online: 12 February 2021

\section{References}

1. Vasen HF, Mecklin JP, Khan PM, Lynch HT. The international collaborative group on hereditary non-polyposis colorectal Cancer (ICG-HNPCC). Dis Colon Rectum. 1991;34(5):424-5.

2. Umar A, Boland CR, Terdiman JP, Syngal S, de la Chapelle A, Rüschoff J, et al. Revised Bethesda guidelines for hereditary nonpolyposis colorectal cancer (Lynch syndrome) and microsatellite instability. J Natl Cancer Inst. 2004;96(4):261-8.

3. Bengtsson D, Joost P, Aravidis C, Askmalm Stenmark M, Backman AS, Melin $B$, et al. Corticotroph pituitary carcinoma in a patient with Lynch syndrome (LS) and pituitary tumors in a Nationwide LS cohort. J Clin Endocrinol Metab. 2017;102(11):3928-32.

4. Rubenstein JH, Enns R, Heidelbaugh J, Barkun A. Clinical Guidelines Committee collaborators. American Gastroenterological Association Institute guideline on the diagnosis and Management of Lynch Syndrome. Gastroenterology. 2015;149(3):777-82

5. Statistik om nyupptäckta cancerfall 2018.2019. 14 January 2020.]. In Swedish. Available from: https://www.socialstyrelsen.se/globalassets/sharepointdokument/artikelkatalog/statistik/2019-12-6523.

6. Hampel H, Frankel WL, Martin E, Arnold M, Khanduja K, Kuebler P, et al. Screening for the Lynch syndrome (hereditary nonpolyposis colorectal cancer). N Engl J Med. 2005;352(18):1851-60.

7. Thompson BA, Spurdle AB, Plazzer JP, Greenblatt MS, Akagi K, Al-Mulla F, et al. Application of a 5 -tiered scheme for standardized classification of 
2,360 unique mismatch repair gene variants in the InSiGHT locus-specific database. Nat Genet. 2014;46(2):107-15.

8. Hospital facts 2019. 14 January 2020. Available from: https://www.karolinska. se/om-oss/organisation/Fakta-om-sjukhuset-Verksamhetsplaner\%2D\%2 Darsberattelsen\%2D\%2Dpresentationsbroschyrer\%2D\%2Dorganisation/.

9. Statistics in Stockholm (Befolkningen i Stockholms län 2018-2019). 14 January 2020. Available from: https://www.sll.se/globalassets/4.regionalutveckling/publicerade-dokument/a5\%2D\%2D-kv4-2018.

10. Statistics in Sweden Sveriges befolkning 2019. 14 January 2020. Available from: https://www.scb.se/hitta- statistik/sverige-i-siffror/manniskorna-isverige/sveriges-befolkning.

11. Hampel $\mathrm{H}$, de la Chapelle A. The search for unaffected individuals with Lynch syndrome: do the ends justify the means? Cancer Prev Res (Phila). 2011;4(1):1-5.

12. Win AK, Lindor NM, Young JP, Macrae FA, Young GP, Williamson E, et al. Risks of primary extracolonic cancers following colorectal cancer in lynch syndrome. J Natl Cancer Inst. 2012;104(18):1363-72.

13. Lynch HT, de la Chapelle A. Hereditary colorectal cancer. N Engl J Med. 2003;348(10):919-32.

14. Increasing the age limit for Lynch syndrome genetic testing may save lives. 2017. 10 December 2020. . Available from: https://www.eshg.org/index. php?id $=13 \& L=0$

15. Mittendorf KF, Hunter JE, Schneider JL, Shuster E, Rope AF, Zepp J, et al. Recommended care and care adherence following a diagnosis of Lynch syndrome: a mixed-methods study. Hered Cancer Clin Pract. 2019;17:31.

16. Singh H, Schiesser R, Anand G, Richardson PA, El-Serag HB. Underdiagnosis of Lynch syndrome involves more than family history criteria. Clin Gastroenterol Hepatol. 2010;8(6):523-9.

17. Cross DS, Rahm AK, Kauffman TL, Webster J, Le AQ, Spencer Feigelson $H$, et al. Underutilization of Lynch syndrome screening in a multisite study of patients with colorectal cancer. Genet Med. 2013;15(12):933-40.

18. Adelson M, Pannick S, East JE, Risby P, Dawson P, Monahan KJ. UK colorectal cancer patients are inadequately assessed for Lynch syndrome. Frontline Gastroenterol. 2014;5(1):31-5

19. Menko FH, Ter Stege JA, van der Kolk LE, Jeanson KN, Schats W, Moha DA et al. The uptake of presymptomatic genetic testing in hereditary breastovarian cancer and Lynch syndrome: a systematic review of the literature and implications for clinical practice. Familial Cancer. 2019;18(1):127-35.

20. Suthers GK, Armstrong J, McCormack J, Trott D. Letting the family know: balancing ethics and effectiveness when notifying relatives about genetic testing for a familial disorder. J Med Genet. 2006;43(8):665-70.

21. Aktan-Collan Kl, Kääriäinen HA, Kolttola EM, Pylvänäinen $\mathrm{K}$, Järvinen $\mathrm{HJ}$, Haukkala AH, et al. Sharing genetic risk with next generation: mutationpositive parents' communication with their offspring in Lynch syndrome. Familial Cancer. 2011;10(1):43-50.

22. Leenen $\mathrm{CH}$, Heijer M, van der Meer C, Kuipers EJ, van Leerdam ME, Wagner A. Genetic testing for Lynch syndrome: family communication and motivation. Familial Cancer. 2016;15(1):63-73.

23. Petersen HV, Frederiksen BL, Lautrup CK, Lindberg L, Ladelund S, Nilbert M. Unsolicited information letters to increase awareness of Lynch syndrome and familial colorectal cancer: reactions and attitudes. Familial Cancer. 2019; 18(1):43-51.

24. Dheensa S, Fenwick A, Lucassen A. 'Is this knowledge mine and nobody else's? I don't feel that.' Patient views about consent, confidentiality and information-sharing in genetic medicine. J Med Ethics. 2016;42(3):174-9.

\section{Publisher's Note}

Springer Nature remains neutral with regard to jurisdictional claims in published maps and institutional affiliations.

Ready to submit your research? Choose BMC and benefit from:
- fast, convenient online submission
- thorough peer review by experienced researchers in your field
- rapid publication on acceptance
- support for research data, including large and complex data types
- gold Open Access which fosters wider collaboration and increased citations
- maximum visibility for your research: over 100M website views per year
At BMC, research is always in progress.
Learn more biomedcentral.com/submissions

